\title{
Diálogos a partir de Walter Benjamim: a figura de Maiakovski como elo de ligação entre o cubofuturismo e o formalismo russo
}

\section{Dialogues from Walter Benjamin: the figure of Mayakovsky as the connecting link between Cubo-Futurism and Russian formalism}

\author{
Carolina Izabela Dutra de Miranda \\ Universidade Federal de Minas Gerais (UFMG), Belo Horizonte, Minas Gerais / Brasil \\ carolina.miranda@santoagostinho.com.br
}

Resumo: O presente trabalho aborda as especificidades do futurismo russo, nomeado cubofuturismo, a partir das colocações de Walter Benjamim, presentes nos textos "A nova literatura Russa" (1927) e "O agrupamento político dos escritores na União Soviética" (1927). Embasando-se na discussão desses textos, pretende-se esclarecer a relação deles com o formalismo russo, importante movimento crítico que ocorreu contemporaneamente ao cubofuturismo. Para tanto, pretende-se explicitar como a figura de Vladimir Maiakovski estabeleceu um elo de ligação entre esses dois movimentos - o crítico e o literário - e de que forma o poeta tornou-se importante marco para o cubofuturismo russo e para engajamento político social do movimento literário. Este trabalho pretende expandir as informações e as visões apresentadas por Benjamim em seus textos, sobretudo em relação à atualização acerca do progresso destes movimentos literários e à importância deles, que dificilmente poderiam ser antevistos pelo teórico alemão no momento de produção de seus escritos.

Palavras-chave: Cubofuturismo; Futurismo; Formalismo russo; Maiakovski.

Abstract: This study aims to deal with the singularities of Russian futurism, named Cubo-Futurism, based on the writings of Walter Benjamin, exposed in the texts "New Russian Literature" (1927) and "The Political Groupings of Russian Writers" (1927). Based on the discussion of these texts, it is intended to clarify their relationship with Russian formalism, an important critical movement which happened contemporaneously with Cubo-Futurism. For this purpose, it aims to explain how the figure of Vladimir 
Mayakovsky established a connecting link between these two movements - the critic and the literary - and how the poet became an important symbol for Russian CuboFuturism and also for the social and political engagement of the literary movement. This study intends to expand the information and the aspects exposed by Benjamin in his texts, especially in relation to the update on the progress of these literary movements and the importance of them, which could hardly be foreseen by the German theorist at the time of his writings.

Keywords: Cubo-Futurism; Futurism; Russian formalism; Mayakovsky.

\section{Introdução}

No texto "A nova literatura Russa", publicado em 1927, Walter Benjamim afirma que a literatura russa daquele período assumiu uma espécie de condição fisiológica de aliviar o corpo do povo em relação à sobrecarga das experiências vividas. Dessa forma, a literatura foi vista como um processo de eliminação, tendo um significado higiênico e terapêutico, em que as pessoas passavam a somente conseguir se comunicar umas com as outras em uma linha de fuga de uma tendência, inseridas na perspectiva do comunismo. Esse contexto cultural gerou uma multiplicidade de produções artísticas. Sendo assim, a literatura russa tornou-se mais precursora de uma nova historiografia do que de uma nova beletrística, em que passa a ser vista como uma forma de acesso ao fenômeno moral da Revolução Russa, constituindo o movimento artístico do cubofuturismo russo.

Esse trabalho objetiva partir das colocações de Walter Benjamim sobre o futurismo, presentes nos textos "A nova literatura Russa" (1927) e "O agrupamento político dos escritores na União Soviética" (1927), para tratar das especificidades do futurismo russo, nomeado cubofuturismo. Com base na discussão dos textos, pretende-se esclarecer sua relação com o formalismo russo, importante movimento crítico que ocorreu contemporaneamente ao cubofuturismo. Para tanto, pretendese explicitar como a figura de Vladimir Maiakovski estabeleceu um elo de ligação entre estes dois movimentos - o crítico e o literário - e de que forma o poeta tornou-se importante marco para o cubofuturismo russo e o engajamento político social desse movimento. Este trabalho visa expandir as informações e as visões apresentadas por Benjamim em seus textos, sobretudo em relação à atualização acerca do progresso 
destes movimentos literários e à importância deles, que dificilmente poderiam ser antevistos pelo teórico alemão no momento de produção de seus escritos.

\section{O surgimento do cubofuturismo russo: contexto histórico e social}

O crítico Walter Benjamim propõe que a origem do futurismo russo nasce das condições socioculturais da Rússia em meados de 1917. A derrocada do império de Tzar, líder da nobreza russa, e o avanço do comunismo russo, tendo como líderes Lênin e Trotsky, propiciaram um contexto adequado para o surgimento de um movimento que expressasse a quebra da aristocracia literária e da ideologia burguesa. Esse rompimento deu origem ao futurismo, um movimento de negação às formas de arte anteriormente predominantes na Rússia, como o simbolismo e o realismo. Assim, propõe um projeto literário que busca uma forma de arte autônoma e engajada com o momento social. Nesse sentido, a destruição dos cânones artísticos rígidos, baseados em leis técnicas e teorias, leva ao surgimento de verdadeiros talentos, como Maiakovski, que aproveitaram essa nova liberdade artística para realizar criações geniais para a literatura russa.

Benjamim propõe que, além da situação de extrema pobreza e penúria das classes baixas, que eram contra o regime de Tzar e a ideologia burguesa, o movimento sofre com algumas dificuldades.

Os próprios teóricos do bolchevismo enfatizam quão pouco a situação do proletariado na Rússia, depois de sua revolução vitoriosa de 1918, se pode comparar com a da burguesia na França, em 1789. Naquela época, a classe vitoriosa, antes de tomar o poder, se assegurara o domínio do aparato intelectual por meio de lutas de várias décadas. A organização intelectual e a educação tinham sido penetradas pela ideologia do tiersétat, ${ }^{1}$ havia muito tempo, e a luta pela emancipação intelectual havia sido travada antes da luta política. Na Rússia de hoje a situação é bem diferente. Para milhões e milhões de analfabetos, os fundamentos de uma educação geral ainda precisam ser colocados. (BENJAMIN, 1927, p. 101)

1 "O Terceiro Estado" é um texto político, escrito em 1789, pelo escritor, eclesiástico e político francês Emmanuel Joseph Sieyès. Nesse texto, o autor fala que o terceiro estado é uma nação completa e que não necessita dos outros dois estamentos: o clero e a nobreza. 
O crítico explica que Lênin, ao propor sua luta contra o império russo e tomar o poder, propõe três frentes em seu governo para mobilizar a população e a cultura: a (I) frente política, a (II) frente econômica e a (III) frente cultural. A relação íntima entre contexto político e produção literária será melhor trabalhada por Benjamim em seu artigo "O agrupamento político de escritores na união soviética" (1927), em que se destaca que o regime ditatorial russo faz com que a exposição do trabalho dos escritores russos e seu controle sejam bem maiores em relação aos escritores ocidentais. Tal controle ocorre inclusive por meio de uma censura prévia do partido aos livros que serão publicados e, por isso, a tomada de posição e o engajamento dos escritores russos são considerados vitais.

Ainda nesse texto, Benjamim explica o surgimento da VAPP, Associação Pan-russa de escritores proletários ${ }^{2}$, constituída por 7.000 membros, que objetiva abrir espaço para a expressão do proletário russo nas artes. Porém, como os meios organizatórios e produtivos ainda se encontram nas mãos da burguesia, o proletariado acaba por não lograr sua expressividade nos campos da arte e da literatura. O crítico chama a atenção para as divisões e lideranças dentro do grupo como os "napostovtzi" - assim chamado por causa de sua revista Na Postu (No posto). Sob a liderança de Leopold Leonidovich Averbakh, ela representa a ortodoxia partidária propriamente dita. Os representantes teóricos do grupo são Lelévitch e Besymênski. Os trabalhos de Lelévitch tentam aperfeiçoar as bases da estética materialista de outro importante escritor do futurismo russo, Guiorgui Valentinovitch Plekhanov. ${ }^{4}$

\footnotetext{
${ }^{2}$ AAssociação dos Poetas Operários (VAPP), criada a partir dos programas contra núcleos literários autenticamente revolucionários e vivos e submetida à sujeição burocrática, caiu ideologicamente no abandono e aparentemente não conseguiu unidade moral.

${ }^{3}$ Grupo organizado em torno da Revista Na postu, que representava uma fração extrema e ao mesmo tempo líder, representa ainda a ortodoxia propriamente dita. Formado por escritores como Demian Bédny, Juri Nikolajewitsch Libedínski e Alexander Serafímowitsch.

${ }^{4}$ Guiorgui Valentinovitch Plekhanov nasceu em 29 de novembro de 1856 e morreu em 17 de maio de 1918. Pertenceu à primeira geração de marxistas russos. Foi o principal propagandista do materialismo histórico e dialético em sua geração e seus textos tiveram grande influência junto aos lutadores sociais do século XX. Aliado dos mencheviques, ironicamente quem melhor esclareceu o papel do indivíduo nas transformações históricas, não apoiou a maior revolução de sua época.
} 
Em sua obra $A$ história da literatura russa (1948), Paulo Chostakowsky explica que o contexto histórico e social que culmina na origem do futurismo é iniciado em 1894, com a morte de Alexandre II, que leva o povo à perda da confiança no governo. Alexandre II é sucedido por Nicolau II, que, indeciso e vacilante, esfacela o prestígio e a autoridade do império e origina uma onda de descontentamento geral. O regime em derrocada busca sua salvação no êxito militar ocorrido entre 1904-1905 na guerra russo-japonesa, sucedida pela primeira revolução popular, que será sufocada pelo império. Diante da situação de pobreza e dos métodos repressivos do governo, a população mostra-se indignada. Sem saber conduzir esse fracasso, a falência da autoridade tzarista foi total em 1917. Chostakowsky caracteriza a primeira parte da Revolução Russa como política e intelectual, em que a família do Tzar tenta recuperar o poder do regime, que se forma no seio da Duma do império. Já a segunda fase será caracterizada como popular e será marcada pela volta de Lênin de seu exílio na Suíça, assumindo a liderança do grupo dos Bolcheviques em oposição aos Mencheviques, liderados por Julius Martov. Assim, a propaganda Bolchevique desenvolve-se amparada na revolução popular e toma o poder. De acordo com o historiador, neste contexto, a partir de 1917, a literatura russa divide-se em dois ramos: literatura de exílio e literatura soviética, não havendo, portanto, literatura russa fora deste conceito nacional.

\section{O surgimento de uma nova literatura russa: origens e desdobramentos}

Benjamim esclarece que esse contexto de decadência político social levou ao surgimento de organizações, jornais e revistas que se propuseram ao engajamento social, tentando expressar o sentimento das classes operárias e camponesas, como a publicação do jornal Pravda ${ }^{5}$. A VAPP acredita que somente o escritor proletário de verdade se identificaria com a ditadura do proletariado. Ao mesmo tempo surgiriam

\footnotetext{
${ }^{5} \mathrm{O}$ Pravda, que em russo significa verdade, foi o principal jornal da União Soviética e um órgão oficial do Comitê Central do Partido Comunista da União Soviética entre 1918 e 1991. O jornal ainda existe e está em circulação na Rússia, mas ficou mais conhecido nos países ocidentais por seus pronunciamentos durante o período da Guerra Fria. O Pravda original foi fundado por Leon Trotsky, Victor Kopp, Adolf Joffe e Matvey Skobelev como um jornal socialdemocrata russo semanal voltado para os operários, chamado Zvezda. O periódico era publicado no exterior, para evitar censura, e de lá era enviado para dentro da Rússia.
} 
também grupos patrióticos nacionalistas de direita, como os popútchki. Esse grupo teve dois principais representantes: Iessenin e Ehrenburg. Iessenin é caracterizado pelo crítico como "a personificação brilhante e irradiante de um tipo russo "antigo", o sonhador profundo e caoticamente telúrico e atormentado pela dor, um tipo inconciliável como o homem novo criado na Rússia pela Revolução" (BENJAMIN, 1927, p. 99).

Esse grupo de direita foi representado por escritores como Vorónski e Efros. Vorónski assimila a teoria de Trotski e conclui que o operariado não conseguirá até aquele momento ter força o suficiente para produzir uma literatura proletária. Esse foi o projeto, também fracassado da chamada Proletkult, uma organização que tinha como principal objetivo fomentar o surgimento de escritores operários, que tomassem as rédeas da produção cultural literária. Esse grupo foi formado por imagistas e construtivistas que, de forma análoga aos surrealistas franceses, produziam uma poesia de base associativa, apresentando sequências de períodos desconexos. Os construtivistas seriam conhecidos pela busca em levar a palavra a um efeito máximo, tendo como principal exemplo o alemão August Stramm ${ }^{6}$.

De acordo com Thales Camelo da Costa, em seu artigo "Democratização Proletkult" (2008), a lógica desta associação é de que, se a revolução era dos trabalhadores, cabia a eles lançar os fundamentos da cultura da nova sociedade. Porém, os fundadores haviam se esquecido de que o processo de divisão de trabalho e de estruturação da sociedade em classes fez com que o acesso à alfabetização e à cultura se tornassem possíveis apenas para as classes privilegiadas. Leon Trotski diagnosticou em sua obra Literatura e revolução (1923) o avanço do futurismo russo. Segundo ele, enquanto "a burguesia chegou ao poder completamente equipada com a cultura de sua época, o proletariado só chega ao poder completamente equipado com a necessidade aguda de conquistar a cultura" (TROTSKI apud COSTA, 2008, p. 2).

Esta obra de Trotsky também será citada por Walter Benjamim em seu texto "A nova literatura" (1927), em que se destaca que Trotski

\footnotetext{
${ }^{6}$ August Stramm (1874-1915), poeta alemão. Formado em Filosofia na universidade de Halle, trabalhou como inspetor dos correios em Bremen. Convocado para lutar na I Guerra Mundial, faleceu em combate na frente russa. O poeta, que integrou o grupo da revista literária Der Sturm, foi um dos autores mais talentosos e inventivos do expressionismo alemão, abandonando a métrica e fraturando a sintaxe de forma radical.
} 
foi o primeiro a lançar o debate para a proletkult sobre a possibilidade de sucesso do grupo em formar escritores proletários: "Quando se quer de verdade uma literatura de proletários, tem de se começar pela pergunta: Será que hoje em dia, na época da guerra civil, no momento da mais ferrenha luta pela existência, o proletariado tem forças disponíveis para a literatura, para a poesia?" (BENJAMIN, 1927, p. 103). O crítico também fez referência aos questionamentos de Maiakóvski, integrante da Proletkult, pois o poeta afirmava que o grupo queria levar a nova literatura para as massas, queria conquistar o direito da existência literária em relação à máquina e levá-lo para o cotidiano da fábrica. Entretanto, a situação de analfabetismo e ignorância cultural dos operários, vítimas do regime de servidão, fez com que esses não conseguissem entender os intelectuais futuristas e seu engajamento social.

O fracasso do Proletkult pode ser melhor compreendido por meio das colocações sobre a situação dos trabalhadores e dos camponeses na Rússia, propostos na crítica de Liev Tolstói por Rosamund Bartlett. Ela explica que, em 1890, menos de $6 \%$ da população camponesa e proletária era alfabetizada, pois em várias regiões não havia escolas públicas. Outro fator era a persistência em várias propriedades rurais do sistema de servidão, pois a Rússia neste período ainda apresentava traços do feudalismo, já que muitos de seus servos ainda eram considerados "escravos" dos fazendeiros. $\mathrm{Ou}$, apesar de terem conquistado sua liberdade oficialmente, esses servos não tinham para onde ir e continuavam a trabalhar nas fazendas, dando continuidade à sua situação de penúria, miséria e subserviência aos fazendeiros. Segundo Bartlett, "muitos nobres julgavam como seu direito divino a posse de escravos, por isso, a seu ver, o ato de emancipação da servidão era um desastre. Na opinião deles, eles haviam sido roubados por Alexandre II. Eles se perguntavam que diabos um servo faria com a 'liberdade pessoal?'” (BARTLETT, 2013, p. 191). Somente em 1861, os servos se tornam de fato livres, por meio de um discurso de Alexandre II, em abril de 1856, em que ele declarou que "era melhor que a servidão fosse abolida 'de cima para baixo' do que permitir que ela fosse abolida 'de baixo para cima"” (BARTLETT, 2013, p. 169). Essa situação dos servos, junto ao contexto posterior à sua liberdade, com a falta de empregos, a rejeição social para ocupar os postos de trabalho, a fome e a miséria em que se encontraram, análoga à situação dos ex-escravos no Brasil, contribuíram significativamente para a derrocada de Tzar e a ascensão de Lênin, culminando na Revolução Russa. 
Walter Benjamim propõe que, em oposição ao Proletkult, os napóstovtzi é um grupo que se une em torno da revista $\mathrm{Na}$ postu, identificando-se com o programa da VAPP e constituindo um grupo ultra dentro do partido Bolchevique. Esse grupo propõe a impossibilidade da criação de uma literatura produzida pelo proletariado. Nesse sentido, a literatura poderia seria vista como um meio de cooperação pacífica. Para os napóstovtzi, a arte literária também passou a ser uma espécie de arena onde acontece a luta de classes entre o proletariado e a burguesia. Dessa forma, mais que produzir e criar uma literatura proletária, seria necessário reconhecer o princípio hegemônico dessa literatura e o princípio da luta que esta travaria, deglutindo aspectos da cultura burguesa e pequeno-burguesa.

Outro grupo de escritores originado neste contexto é aquele que resulta da NEP (Nova Política Econômica), representado por artistas como: o novelista Pliniák, os dramaturgos Alexiei Tolstói (Primo de Liev Tolstói) e Buklgákov ${ }^{7}$. Outro escritor que pôs sua obra a serviço da Revolução foi Vsévolod Mayerhold ${ }^{8}$, dramaturgo que marcou inovações, como a recusa ao misticismo no palco, as peças sem cortina e luzes de ribalta, com uma cenografia móvel e o palco aberto, demonstrando a busca de uma sinceridade artística. Torna-se conhecido por propor a dramatização de um romance de outro escritor futurista: Iliá Ehrenburg9 9 .

\footnotetext{
${ }^{7}$ Mikhail Bulgákov (15 de maio de 1891, Kiev - 10 de março de 1940, Moscou) foi um escritor russo da primeira metade do século XX. Ele é considerado um dos maiores escritores russos modernos. Também atuou como dramaturgo. Um de seus trabalhos mais conhecidos é o romance fantástico $O$ mestre e Margarida, que se trata de uma narrativa revolucionária, na qual se conta a vinda de uma visita estranha na Moscou comunista dos anos 1930, e que era nada mais que a figura do diabo.

${ }^{8}$ Vsévolod Meyerhold, que nascera em Penza, na Rússia central, em 1874, desde muito jovem tem contato com a arte por intermédio de sua mãe, que transmitiu ao filho o gosto pela música e por espetáculos. Sua primeira experiência teatral foi aos 18 anos com teatro amador em uma representação escolar, onde atuou e também foi assistente de direção. Meyerhold foi para Moscou estudar Direito, mas abandona o curso e entra na Escola Dramática. Participa do Teatro de Arte Moscou, fascinando-se pela arte de Stanislaviski. Após algumas experiências no T.A.M, Meyerhold começa a discordar do conceito stanislavskiano e, em 1902, separa-se de seus mestres e junto com Kocherov monta um grupo chamado "Sociedade do drama novo "com a tentativa de contrapor a estética naturalista".

9 "Ilía Ehrenbur - A verdadeira vocação deste escritor é o jornalismo, e algumas de suas notas publicadas no transcorrer da última guerra mundial chamaram a atenção
} 
Por fim, Demian Bédni será um escritor de engajamento destacado, pela produção de seus cartazes e manifestos.

\section{O cubofuturismo e a figura de Maiakovski}

De acordo com Bruckner, em 1909, os movimentos de escritores russos dividiram-se, em continuações dos decadentes, em ego inumeráveis e cubofuturistas, em que predominava a divisão da necessidade de ebulição da consciência e a falta de objetividade e de conteúdo da obra literária. Posteriormente houve uma lenta transição desses aspectos, parte deles culminará no chamado cubofuturismo. Assim, de acordo com Ripellino, em 1910, surge o Almanaque Sadóksudiéi ( $O$ viveiro dos árbitros), redigido por Vielímir Khliébnikov, David e Nicolai Burliuk, Vassili Kamiênski e Elena Guro. Primeiramente, o grupo denomina-se "Guiléia", posteriormente rebatiza-se por Khliébnikov com as palavras russas: "'Budietliane' (de 'budu', futuro de 'bit' = ser), revelando-se o seu amor pelas civilizações remotas e pelos fatos mitológicos" (RIPELLINO, 1971, p. 15). Os cubofuturistas construíram as poesias líricas com emplastos cromáticos e relações de volumes. Suas produções foram marcadas pela rudeza arrojada do verso, pela superposição de planos semânticos opostos e pela consistência tangível dos objetos. De acordo com Ripellino, para os cubofuturistas:

A poesia não é mais um espelho de reflexos fulgurantes, uma distensão polida, como na época do simbolismo, mas uma escabrosa sequência de torções e desmoronamentos. [...] Muitos elementos do léxico, nas suas estrofes, são tirados em peso do repertório dos pintores cubistas. Vejam-se as letras do alfabeto, que Maiakóvski introduz nos versos como marionetes sonoras e khliébnikov faz até recitar na tragicomédia Zanguei, ou nos letreiros, em que Maiakovski aparece com uma frequência obsessiva. (RIPELLINO, 1971, p. 33)

geral. Como produção literária, sua obra mais notável é certamente $A$ queda de Paris, romance que tem grande valor histórico internacional, pois explica não só os motivos da decadência como também o processo da derrocada de uma grande nação. É possível que a profissão de jornalista tenha imposto a Ehrenburg o estilo telegráfico deste romance. Porém, sob o ponto de vista puramente artístico, esses períodos breves, que se sucedem com uma aspereza rápida a um efeito muito adequado ao tema, obrigam o leitor a entrar no ritmo do relato, que se desenvolve com a nervosidade própria da época conturbada de pré-guerra e da guerra mundial. Ehrenburg era um homem de grande erudição e viveu em Paris vários anos.” (CHOSTAKOWSKY, 1948, p. 343-345) 
O cubofuturismo russo se diferiu do futurismo de Marinetti não apenas porque baseou-se em aspectos do cubismo, mas também porque renegou o futurismo italiano como escola, procurando aproximar-se do proletariado e de suas questões. Um exemplo claro disso foi visto no fato de que Maiakovski recusou-se a encontrar Marinetti quando o líder futurista visitou a Rússia, em 1914. ${ }^{10}$ Outro aspecto que diferenciou o cubofuturismo consistiu no fato de que o futurismo italiano propunha a destruição e a negação de todos os movimentos literários anteriores ao surgimento das vanguardas. Já o cubofuturismo dialoga com a literatura tradicional, sobretudo devido a Voronsky, redator do "Krug" e do "Krasnaia Novi", que exaltou os escritores contemporâneos que retomaram os textos dos clássicos realistas. De certa forma, a produção das obras nessa vanguarda russa fundamentou-se em certas conquistas já realizadas. Esse retorno à tradição foi realizado de maneira mais marcada nos "equilibrismos" de Biély e na prosa eclética de Pliniak. Em $L a$ história de la literatura Russa (1929) Bruckner afirma que "a literatura russa não se propõe a aproveitar velhas embalagens para transformar o velho em novo, e sim que ela se impõe com a pauta da precisão, a simplicidade, a claridade e o conhecimento da vida em seu profundo dinamismo" (BRUCKNER, 1929, p. 313).

Outro exemplo destacado por Benjamim que comprovou essa tendência de retorno a movimentos anteriores, distinguindo-se, portanto, do futurismo, foi o poeta simbolista Valeri Briussov, ${ }^{11}$ pertencente ao

10 "No início de 1914, enquanto Maiakóvski e seus amigos continuavam sua tournée, chegou à Rússia Marinetti. Pronunciou três conferências em Moscou (27-28 janeiro, 3 fevereiro) e duas em Petersburgo (1-4 fevereiro) Alguns dias antes da sua chegada, o pintor Mikhail Larionov declarou ao jornal de Moscou que era preciso recebê-lo com ovos podres, porque traíra os princípios por ele mesmo promulgados. Os "buditliane" eram zelosos da própria independência. E na realidade se excluirmos talvez a influência de certos quadros de Boccioni, como Forças de uma estrada, ou as líricas em que Maiakóvski retrata os reveses e as destroncadas convulsões das cidades modernas, existem, na poesia e na pintura, escassas analogias entre o futurismo russo e o futurismo italiano. Entremeados de temas primitivos e asiáticos, e imersos sempre num clima de paganismo eslavo, os escritos de Khliébnikov e de Kamienski estão em contraste direto com as páginas dos futuristas italianos." (RIPELLINO, 1971, pp. 24-25)

${ }^{11}$ Sobre Briussov, o historiador Chostakowsky declarou que "sua grande cultura intelectual e uma capacidade de trabalho superior à normal, unidas a uma vontade sobre-humana de alcançar êxito, conquistara-lhe o posto de relevo no domínio das 
grupo dos outsiders ${ }^{12}$, que não eram ligados a nenhuma tendência, mas eram bastante conhecidos na Europa do período. O poeta russo, que foi considerado o fundador do simbolismo naquele país, foi comparado a ilustres escritores como Stefan George ${ }^{13}$, e se posicionou imediatamente do lado da revolução, quando surgiram as vanguardas na Rússia. Bruckner complementou que os cubofuturistas Maiakovski, Tretiakov e Aseiev também derivaram suas produções de um diálogo com o realismo, demonstrando esses aspectos nas inovações de suas obras e em uma atitude artística cada vez mais voltada para a luta de camponeses e trabalhadores. Ripellino destaca que Púshkin também buscou aprender a língua dos campesinos e aproximou cada vez mais a linguagem e os temas das massas a uma linguagem revolucionária que caracterizava a nova literatura russa, atitude que foi vista em seu ápice com a publicação do poema 150.000.000, de Maiakovski:

150.000.000 é o nome dos autores deste poema

Seu ritmo: a bala.

Sua rima, o fogo saltando de um prédio para o outro.

150.000.000 falam pela minha boca.

letras pré-revolucionárias. De temperamento, Briússov era o que os franceses chamam um piocheur (cavador). Sua aplicação constante, incansável, para suprir o gênio com o esforço é um traço comum entre os homens de ciência, porém raro entre os poetas." (CHOSTAKOWSKY, 1948, pp. 313-314)

${ }^{12}$ Outsider é aquele que não se enquadra na sociedade, que vive à margem das convenções sociais e determina seu próprio estilo de vida, através de suas crenças e valores. Vários escritores e pensadores foram críticos ferrenhos da sociedade em que viveram: através de inúmeros romances e ensaios filosóficos, estes "outsiders" condenaram as práticas e os comportamentos hipócritas de seus contemporâneos.

${ }^{13}$ Poeta germânico nascido em Büdesheim, na Renânia, que impulsionou a nova lírica germânica e se propôs a formar uma nova elite intelectual e revitalizar o ideário estético, contra o naturalismo predominante na época, tornando-se a figura mais representativa do simbolismo alemão. Foi educado no Gymnasium in Darmstadt (1882-1888) e depois viajou pela Europa ocidental. Frequentou cursos de filosofia e de história da arte (1888-1889) e conheceu as principais figuras do simbolismo francês, tornando-se seguidor (1889) da sutileza musical de Verlaine, em Paris. Com Das neue Reich (1928) elaborou um autêntico manifesto profético, no qual anunciava o reino do espírito, que se identificava com o renascimento dos valores da antiga Grécia. Convidado pelos nazistas a aderir a suas fileiras, quando da ascensão de Hitler (1933), optou pelo exílio voluntário e morreu em Minusio, Locarno, Suíça, naquele mesmo ano. 
Esta edição foi impressa com a rotação dos passos, no papel velino empedrado.

Quem pergunta a lua?

Quem pretende que o pôr do sol lhe preste contas?

Quem ousaria afirmar:

Este é o autor mais genial do mundo?

Da mesma forma

esse poema

não tem autor

Sua única ideia é

brilhar no dia nascendo

esse mesmo ano, nesse dia e hora,

no subterrâneo, na terra pelo céu e até mais alto

apareceram estes

cartazes,

folhetos,

propagandas:

"A TODOS! A TODOS! A TODOS!

Para todos aqueles que não aguentam mais!

Saiam e vamos juntos! (MAIAKOVSKI, 1920)

O poema foi uma tentativa de Maiakovski de dar voz aos camponeses e trabalhadores russos que lutavam por melhores condições de sobrevivência durante a Revolução Russa. O engajamento do poeta também foi visto na utilização de cartazes e objetos animados, sob clarões de luzes dos automóveis e nos reflexos dos faróis, misturando a temática político-social às novas técnicas de produção. Walter Benjamim caracterizou Vladimir Maiakovski como um "frondista excêntrico", um "Dândi egocêntrico", que em 1920 colocou seu talento teatral a serviço da revolução. Para Benjamim "O poema '150.000.000', pela primeira vez, pôs as conquistas formais do futurismo a serviço da propaganda política. A fala da rua, a bagunça fonética, a baderna imaginosa comemoram a nova época da dominação das massas" (BENJAMIN, 1927, p. 102).

Outras técnicas utilizadas pelos escritores cubofuturistas eram percepções gráficas expressas por meio de caligramas ou dissecando palavras em partículas fonéticas. Assim as coletâneas de Kamiênski, Tangos Koróvami (Tango com as vacas) e Nagóisriediodietikh (Nu entre gente vestida), de 1924, foram impressas com impressões pictóricas em papel de formato pentagonal. Outra técnica foi a publicação de versos 
como manuscritos litografados, em que borrões e manchas assumiram uma função decorativa. Por meio de análises e decomposições de palavras, os cubofuturistas chegaram a uma linguagem transmental ("zaúmni iajik"), em que eram balbuciados vocábulos inexistentes, misturando tramas fonéticas abstratas, como nos versos rangentes, de 1912, de Krutchônikh: "Dir- bulchchil/ Ubieiur/ Skum/ vi- so-bu/ r - 1 - ez" (RIPELLINO, 1971, p. 36). Em abril de 1913, Krutchônikh: publicou a Deklarátzia slova kak takovo (Declaração da palavra como tal), propondo que "As palavras morrem, o mundo é eternamente jovem. O artista vê o mundo de maneira nova e como Adão dá um nome a cada coisa. O lírio é belíssimo, mas é feita, violada e consumida a palavra 'lília'. Portanto eu o chamo 'eu', devolvendo-lhe a pureza primitiva” (RIPELLINO, 1971, p. 36). Assim, em suas produções, Krutchônikh inventou palavras e expressões nunca ouvidas, que pareciam ser retiradas de um nexo selvagem, além de dar preferência a dissonâncias bruscas, monossílabos guturais, locuções contraídas e crepitantes. Também Maliévitch trabalhou com novas formas de produção literária e publicou o manifesto "Do cubismo ao suprematismo", de junho de 1915, em que propõe que o cubofuturismo foi uma forma de encaminhamento à pesquisa das formas abstratas, em uma pintura fundada na intuição, na supremacia dos sentimentos, despida de qualquer relação com o mundo exterior. De acordo com o escritor, o suprematismo nasceu da busca em "devolver uma pureza primitiva à superfície pictórica" (RIPELLINO, 1971, p. 38).

Benjamim ressaltou outros escritores que se destacaram no movimento cubofuturista como Aleksander $\mathrm{Blok}^{14}$, que se tornou famoso na Alemanha por suas tentativas de unir o misticismo religioso com o delírio dos anos de revolução. Na Revista Katórga, os escritores vítimas da prérevolução, que foram banidos para a Sibéria, publicaram suas anotações, como Vera Figner, que posteriormente publicou a obra Noite sobre a Rússia. Outros autores foram perseguidos pela Tcheká (Polícia Secreta

\footnotetext{
${ }^{14}$ Aleksandr Blok é um dos maiores poetas de língua russa. Dramaturgo e crítico literário, Blok tornou-se um dos reconhecidos gênios da Era de Prata. Nascido em São Petersburgo, a 28 de Novembro de 1880, o autor viveu e trabalhou na viragem de duas épocas históricas e foi o último grande poeta da Rússia pré-revolucionária que concluiu na sua obra as buscas poéticas de todo o séc. XIX. Ao mesmo tempo, o seu nome abre a primeira página da história da poesia soviética russa. Blok traduziu Byron, Heine e as trovas de Rutebeuf.
} 
Revolucionária $)^{15}$, por isso essa perseguição tornou-se uma área temática para escritores como Tárassov-Rodionov, Slonímski e Grigónev. A autora Lídia Seifulina dedicou-se especialmente ao estudo dos "besprizórni,", menores abandonados que andarilhavam pela Rússia. Outros cubofuturistas e suas respectivas obras que mereceram destaque são Iúri Lebedínski, Uma semana; Ivanov ${ }^{16}$, Ventos coloridos, O trem blindado 19-69; Dibenko, Larissa Reisner, importante jornalista, Sosonóvski e Fiódor Gladkóv. O crítico chamou a atenção para o papel de líder exercido por Maiakovski, integrante de grupos como: os popútchiki de esquerda, originado da Lef - Líevi Front ou Frente de Esquerda (1923-1925) - que era um agrupamento de artistas que se propuseram à tarefa de desenvolver formas revolucionárias, além de liderar um dos primeiros grupos da Proletkult.

No estudo Maiakovski e o teatro de vanguarda (1971), Angelo Maria Ripellino, conta que Maiakovski infundiu com vigor e impetuosidade o grupo dos 'Budietliane'. Após a morte do pai, em 1906, o poeta se filiou ao partido bolchevique, aos quatorze anos de idade e, em 1911, foi admitido no Instituto de pintura, escultura e arquitetura, onde conheceu David Burliuk. Em sua biografia, o poeta recorda a noite de 4 de fevereiro de 1912 como uma data essencial para a história do cubofuturismo: "O desdém do mestre que tinha superado os contemporâneos, em mim, o pathos de um socialista convencido de que toda velharia seria inelutavelmente derrubada. Nasce o futurismo russo" (RIPELLINO, 1971, p. 17-18). Maiakóvski fez parte do grupo dos cubofuturistas russos que publicaram em 1910 o almanaque Sadóksudiéi

\footnotetext{
${ }^{15}$ A polícia soviética, ou a chamada Tcheka, foi a primeira das organizações de polícia secreta da União Soviética. Ela foi criada por um decreto emitido em 20 de dezembro de 1917, por Vladimir Lenin, e, posteriormente, conduzida pelo aristocrata que se tornou comunista Felix Dzerzhinsky. Sua tarefa era reprimir qualquer ato contrarrevolucionário. Estas tropas policiaram campos de trabalho, o sistema de Gulags, conduziu requisições de alimentos, liquidou os adversários políticos (de direita e esquerda), sufocou as rebeliões camponesas, tumultos por parte dos trabalhadores, e motins no Exército Vermelho. 16 "ViatcheslauIvánov - durante muitos anos foi um sábio arqueólogo e filólogo, um dos homens mais instruídos da Rússia, autor de um tratado latino De societa busrectigalium publicorum Populi Romani. Seus estudos sobre a Grécia antiga, sua religião, filosofia e poesia levaram-no a uma concepção simbolista do universo, que expressou em um grande volume de versos intitulado As estrelas pilotos. Sendo professor de ensino superior, Ivánov conserva ao dedicar-se à poesia o tom e os procedimentos de um sábio universitário. É o único poeta da época em cujos versos não sopra o vento da revolta; é metódico, consequente, respeitável e exato" (CHOSTAKOWSKY, 1948, p. 319).
} 
(Armadilha para juízes). Em 1912, Maiakóvski, juntamente a Khliébnikov, Burliuk e Aléksipei Katchôn, apresenta o manifesto do cubofuturismo, no almanaque Pochchótchinaobchchéstvienomuvkússu (uma bofetada no gosto público), exaltando a repulsão dos escritores realistas e proclamando o direito dos poetas de "aumentar o volume do vocabulário com as palavras arbitrárias e derivadas" (RIPELLINO, 1971, p. 17-18).

Em A poética de Maiakovski (1971), Boris Schnaiderman parte da colocação de Ripellino de que, nas fotografias e nos versos futuristas, o poeta e teatrólogo Maiakovski posicionava-se como um "malandrogentil-homem" que se "rebaixava" para defender os miseráveis e os aflitos. Para Schnaiderman, o futurismo russo, após a revolução de outubro, foi um movimento protegido pelo regime e considerado uma tendência oficial no campo das artes. Em 1963, L. Pajitnov e B. Chráguin declararam que "O futurismo não foi para Maiakóvski qualquer coisa de superficial e adventício. Em seus lábios soava como um apelo à derrubada das caducas fronteiras da arte burguesa - precisamente da arte decadente - uma palavra de ordem que exortava a criar a cultura artística do futuro" (SCHNAIDERMAN, 1971, p. 23). Em 1929, em um artigo chamado "Uma gôta de fel", Maiakóvski afirma que todos eram futuristas em seu tempo, inclusive o povo, porém a primeira parte do programa futurista russo já havia sido completada e nesse momento iniciou-se a nova fase de construção do futurismo, que foi posteriormente nomeada construtivismo. N. A. Sviertchkóv propõe que "o construtivismo está intimamente ligado ao crescimento da cultura industrial e expressa o seu patos intelectual, técnico e industrial" (SCHNAIDERMAN, 1971, p. 35). De acordo com Schnaiderman, o construtivismo se embasa na ideia da adequação racionalista, na exigência da economia, no cálculo matemático, no laconismo dos meios de expressão artística. A tendência construtivista aproximava a arte e a indústria, renegando o decorativo e esquematizando a lógica e a maquinação da linguagem da arte. Nas formulações mais extremadas do construtivismo, o movimento visava à liquidação da arte como esfera espiritual, à substituição do artista pelo engenheiro, pelo construtor e à dissolução da obra artística na construção da vida e na criação de objetos adequados e racionais. Em 1929, no prefácio para a projetada edição de um almanaque do grupo Ref (O. C. XII, 203, 204), o poeta escreveu: "Nós sabemos - o futuro pertence à máquina fotográfica, à crônica radiofônica, ao jornalismo cinematográfico, mas serão espécies e formas aprofundadas dessas culturas" (SCHNAIDERMAN, 1971, p. 58). 


\section{Maiakovski, o cubofuturismo e o formalismo russo}

Maiakovski foi atuante em várias áreas da arte durante o cubofuturismo, na produção de cartazes em defesa do povo e das necessidades dos trabalhadores, em que demonstrou uma preocupação com a aliança da palavra e da imagem pictórica. Atuou ainda como ator, cenarista e editor nos trabalhos de encenação dirigida (Meyerhold) e no espetáculo "Mistériobufo". Benjamim destaca que essa peça de teatro seria o ápice do sucesso de Maiakovski, por ser "uma apresentação com milhares de atores, alarma de sirenes, música militar, orquestras barulhentas a céu aberto" (BENJAMIN, 1927, p. 102). Também realizou desenhos, como as séries "Prun" e "Lissítzki", que visavam lançar uma ponte entre a pintura e a escultura, e uma integração da palavra à imagem. E, ainda, em fotomontagens, em colaboração com Ródtchenko, e em sua atuação juntamente a Víctor Chklovski e Ossipi Brik como roteiristas. Boris Schnaiderman relaciona a figura de Maiakovski à de Walter Benjamim ao afirmar que:

O cientifismo de Maiakóvski, a aproximação que faz entre a poesia e a ciência e que nos aparece tão poundiana, liga-o a algumas grandes concepções poéticas de nosso século. E a compreensão de que as novas condições do mundo moderno obrigam à busca de outras formas de arte aproxima-o certamente não só de Brecht e Piscator, mas também de Walter Benjamin. Maiakóvski afirmou em diversas ocasiões a necessidade de se anular a diferença rígida entre prosa e verso e, neste sentido, ele prenuncia a noção moderna de texto. Enfim, quando reflete sobre alguns aspectos fundamentais da arte moderna, da poesia moderna, surge soberano o papel precursor de Maiakóvski, sua intuição e perspicácia. (SCHNAIDERMAN, 1971, p. 59)

Além destas aproximações, as técnicas de escrita poética, as experimentações e a desconstrução das palavras em suas produções aproximou Maiakóvski do movimento crítico ocorrido concomitantemente ao cubofuturismo, o formalismo Russo. Apesar de aparentar ser uma relação óbvia, a ligação entre futuristas e formalistas russos não foi discutida por Walter Benjamim e será citada rapidamente por poucos críticos, como Boris Schnaiderman, Boris Eikhenbaum e Leon Trotski.

Para Schnaiderman, a relação entre o poeta e o formalismo foi estreita, já que a atuação dos futuristas russos estava encaminhada para 
a pesquisa de uma linguagem poética vinculada à vida e não petrificada. Em 1913, os cubofuturistas publicaram uma "Declaração da palavra como tal", essa expressão também será utilizada pelos formalistas para indicar a necessidade de um estudo puramente formal da linguagem. No artigo "O dois Tchekhov" (1914), Maiakovski propõe que Tchekhov foi o primeiro escritor russo a compreender que o escritor "apenas modela um vaso artístico", referindo-se, assim, à forma da linguagem. Para Maiakovski, "não é a ideia que engendra a palavra, mas a palavra que engendra a ideia" (SCHNAIDERMAN, 1971, p. 38). Essa proposição aproxima o pensamento de Maiakovski ao de seu amigo, Victor Chklovski - crítico formalista e escritor de roteiros futuristas - pois o poeta aplicava a análise formal ao estudo de várias obras, comparando os versos de Púchkin sobre temas triviais com outros escritores de intenção grandiloquente, escritores com o mesmo metro, ritmo e a mesma entonação. Essa análise se assimilava à desmistificação através da apreciação estilística, que era um dos processos prediletos dos formalistas russos e resultou nos trabalhos mais significativos do movimento. A obra do poeta aproxima-se ainda mais do grupo de críticos devido à sua forma radical e extremada de lutar contra a banalização da linguagem poética em suas produções. Além disso, esteve muito ligado a escritores formalistas que publicaram juntamente a ele na Revista Lef. Assim, para Schnaiderman, a relação de Maiakovski com o formalismo russo ficou fortemente marcada pelo apreço do poeta a uma corrente que permitia ao poeta apoiar-se numa teoria de produção.

Para Boris Eikhenbaum, o que aproximou o movimento cubofuturista do formalismo russo foi a criação de uma língua transracional pelos escritores de vanguarda. A criação dessa língua destacou o valor autônomo das palavras e figurou uma demonstração contra as teorias simbolistas, criticadas pelos formalistas e também pelos cubofuturistas, em uma segunda fase do movimento. Chklovski, paralelamente a Jacobinski, publicou um artigo nomeado "Sobre a poesia e a Língua Transracional" (CHKLOVSKI apud EIKHENBAUM, 1925, p. 10). No texto, o crítico acentuou o aspecto articulatório e destacou o aspecto puramente fônico que possibilitou interpretar a correspondência entre o som e o objeto descrito, ou a emoção apresentada de maneira impressionista. Eikhenbaum esclarece que o aspecto articulatório da língua foi importante para a fruição de uma palavra transracional, em que o prazer, proporcionado pela poesia, estaria contido no aspecto articulatório, no movimento harmônico dos órgãos da fala. Chklovski 
formula o problema geral propondo que as construções transracionais permanecem exteriores à língua, mas elas não seriam as únicas que permaneceriam externas: "os fatos nos incitam a refletir sobre a seguinte questão: as palavras têm sempre um significado na língua poética (e não somente na língua transracional) ou não se nota nesta opinião um ponto de vista do espírito resultante de nossa falta de atenção" (EIKHENBAUM, 1925, p. 11). Assim, conclui-se que a língua poética não é uma língua de imagens e sons do verso, mas ela teria uma significação autônoma, e este fato organiza o reexame da teoria geral da Potebnia, construída a partir da afirmação de que a poesia é uma forma de pensar por imagens.

De acordo com Leon Trotsky, a relação entre o formalismo russo e o futurismo russo é paradoxal, uma vez que o formalismo foi a única teoria que se opôs ao marxismo como teoria da arte, em contraposição ao futurismo, que estava em alguns momentos ao lado do comunismo. $\mathrm{O}$ escritor destaca que Victor Chklovski era um teórico do futurismo e, ao mesmo tempo, era o chefe da escola formalista. Apesar do caráter reacionário do formalismo, o trabalho de investigação do movimento será extremamente útil. Entretanto, os futuristas, por mais que suas pretensões fossem fundadas ao se reconhecerem como representantes exclusivos da arte, não se podia negar que eles realizaram o processo que prepararia a arte para o futuro. Para o futurismo russo, a forma determina o conteúdo. O cubofuturismo foi então uma nova forma de expressão que nasceu para responder às novas necessidades artísticas.

\section{Considerações finais}

Como se vê, a relação entre futurismo e formalismo é íntima e inegável, sobretudo quando se considera a atuação artística de Maiakovski como fundador e representante do cubofuturismo russo e a utilização que o poeta faz dos procedimentos de análises poéticas do formalismo Russo. Para entender melhor o formalismo russo, propõe-se a visão de alguns críticos que tentaram captar a essência do movimento formalista e de suas técnicas e processos de análise. Um deles será Leon Trotsky, que reconhece a figura de Chklovski, Jirmunski e Jakobson como representantes do formalismo, mas critica a atuação dessa tendência.

Trotsky reconhece que os formalistas estudam a forma e a essência da poesia, e reduz suas tarefas a uma análise sintática, à contagem de vogais e consoantes que se repetem, das sílabas e dos epítetos. Essa análise é sem 
dúvida essencial, necessária e útil para a compreensão do poema e da poética, porém ela também deve ser entendida como parcial, fragmentária, subsidiária e preparatória. Assim, os métodos formalistas puderam ajudar a esclarecer as peculiaridades artificiais e psicológicas da forma, abrindo caminho para uma compreensão artística individual ou de uma escola literária inteira com o ambiente social que a rodeia. $\mathrm{O}$ crítico propõe que a criação artística é sempre um retorno complexo às formas antigas, sob a influência de novos estímulos. Dessa forma, ele entende a arte como uma função subordinada do homem social indissoluvelmente ligado à sua vida e a seu ambiente. Trotsky critica Chklovski, pois, para ele, o crítico formalista chegou à conclusão de que a arte é absolutamente independente do seu ambiente social justamente em um momento em que a história russa foi revelada pela arte com muita franqueza, demonstrando sua dependência espiritual e material das classes, subclasses e grupos sociais determinantes.

Eikhenbaum também fez referência a Chklovski, ao afirmar que o método formal resultou dos esforços para a criação de uma ciência autônoma e concreta. Assim, para os formalistas, o essencial não era o problema do método nos estudos literários, mas da literatura como objeto de estudo. O que caracterizou o formalismo foi o desejo de criar uma ciência literária autônoma a partir das qualidades do material literário. O objetivo dos formalistas foi, então, chegar à consciência histórica dos fatos que se destacam na arte literária. Os formalistas, de certa forma, promovem uma atualização dos métodos críticos, por se voltarem para os problemas teóricos e para uma análise mais aprofundada do seu objeto de estudo, a produção literária. O crítico destaca uma colocação feita por V. Chklovski, em 1914, em uma publicação intitulada $A$ ressurreição da palavra, que demonstra a concepção de percepção artística de Chklovski: "Se queremos dar a definição poética e mesmo artística, é isto que se impõe inevitavelmente: a percepção artística é aquela através da qual nós experimentamos a forma (talvez não somente a forma, mas ao menos forma)" (CHKLOVSKI apud EIKHENBAUM, 1925, p. 10).

Eikhenbaum propõe que, para os formalistas, era necessário reconhecer que o caráter específico da arte consistia na utilização particular do material, era necessário tornar concreto o princípio da sensação da forma, mostrar que esta surgia como resultado de procedimentos artísticos. O texto "A arte como procedimento" (1917), de Victor Chklovski, expôs tais necessidades e representou uma espécie de manifesto do método formal. Nesse texto, Chklovski propõe que a arte é 
pensar por imagens e que a arte seria também uma criadora de símbolos. Propõe ainda que as leis de nosso discurso prosaico, como as frases inacabadas e também as palavras pronunciadas pela metade explicam o processo de automatização do olhar para cenas, objetos e fatos. Assim, o objetivo da arte seria dar a sensação do objeto como visão, e não como um processo de reconhecimento. E um dos procedimentos utilizados pela arte para expressar tais sensações será a "singularização do olhar", exemplificada pelo crítico no conto "Kholstomier", de Liev Tolstói. Essa técnica narrativa consiste em não chamar o objeto pelo nome, mas descrevê-lo "como se o visse pela primeira vez" (CHKLÓVSKI, 1917, p. 46) e tratar cada incidente como se acontecesse pela primeira vez.

Portanto, nota-se que os procedimentos analíticos e a pesquisa sobre o estudo literário dos críticos formalistas, que ocorreram concomitantemente ao futurismo russo, de certa forma, apoiaram o progresso do movimento cubofuturista, auxiliando as técnicas de escrita e produção poética.

Dessa forma, a figura de Maiakovski, produtor de poesias, peças e manifestos do cubofuturismo, associada a publicações e trabalhos cênicos, juntamente a escritores formalistas, indicam o poeta como um possível elo de ligação e de diálogo entre o movimento literário e a tendência crítica. No contexto de produção dos textos de Walter Benjamim, explorados neste trabalho, possivelmente a visão crítica sobre a aproximação entre estes dois movimentos não seria visível, devido às divisões políticas presentes na época. Sendo assim esclarecidas neste trabalho com textos produzidos posteriormente à publicação dos artigos do teórico alemão.

\section{Referências}

BARTLETT, Rosamund. Tolstói: a biografia. Tradução de Renato Marques. São Paulo: Globo, 2013.

BENJAMIM, Walter. A nova literatura Russa. (1927). In:

Documentos de cultura, documentos de barbárie (escritos escolhidos). Seleção e apresentação de Willi Bole. Trad. Celeste H. M. Ribeiro de Souza et al. São Paulo: Editora Cultrix, Editora Universidade de São Paulo, 1986. 
BENJAMIM, Walter. O agrupamento dos escritores na união soviética. (1927). In: . Documentos de cultura, documentos de barbárie (escritos escolhidos). Seleção e apresentação de Willi Bole. Trad. Celeste H. M. Ribeiro de Souza et al. São Paulo: Editora Cultrix, Editora Universidade de São Paulo, 1986.

BRUCKNER, Alexander. História de la Literatura Russa. Trad. Manuel de Montoliu. Barcelona: Labor, 1929.

CHKLOVSKI, Victor. A arte como procedimento. (1917). Trad. Ana Mariza R Filipouski et al. In: Teoria da literatura: Formalistas russos. Porto Alegre: Globo, 1976.

CHOSTAKOWSKY, Paulo. História da Literatura Russa: desde as origens até os nossos dias. Trad. Álvaro Bittencourt. São Paulo: IPE, 1948.

COSTA, Thalles Gomes Camelo. Democratização Proletkult. Disponível em: <http://www.uff.br/revistacontracultura/Proletkult.pdf $>$. Acesso em: 18 jun. 2018.

EIKHENBAUM, Boris. A teoria do "Método formal". Trad. Ana Mariza R Filipouski et al. In: Teoria da literatura: Formalistas russos. Porto Alegre: Globo, 1976.

GUIORGUI V. PLEKHANOV. MARXIST INTERNET ARCHIVE. Disponível em: $<$ https://www.marxists.org/portugues/plekhanov/index. htm>. Acesso em: 18 jun. 2018.

O MESTRE E A MARGARIDA DE MIKHAIL BULGAKOV: UM CLÁSSICO DO ROMANCE RUSSO. Século Diário. Disponível em: $<$ http://seculodiario.com.br/30006/17/>. Acesso em: 18 jun. 2018.

PLIASSOV, Vladimir I. Aleksandr Blok. Disponível em: $<$ http://www. elfikurten.com.br/2016/06/aleksandr-blok.html>. Acesso em: 18 jun. 2018.

RIPELLINO, A. M. Maiakóvski e o Teatro Russo de Vanguarda. São Paulo: Perspectiva, 1971.

SCHNAIDERMAN, BORIS. A Poética de Maiakóvski. São Paulo: Perspectiva, 1971. 
STEFAN GEORGE. Encyclopaedia Britannica. Disponível em: $<$ https:// www.britannica.com/biography/Stefan-George $>$. Acesso em: 18 jun. 2018.

THOMAZ, Dirce; HENRIQUE, Fernanda. Vsvolod Meyerhold. História do Teatro. Disponível em: $<$ http://historiadoteatroelt.blogspot. com/2008/11/vsvolod-meyerhold.html>. Acesso em: 18 jun. 2018.

TROTSKY, Leon. A escola poética formalista e o marxismo. Trad. Ana Mariza R Filipouski et al. In: Teoria da literatura: Formalistas russos. Porto Alegre: Globo, 1976.

ZUNÁI - Revista de poesia \& debates. August Stramm. Disponível em: $<$ http://www.revistazunai.com/traducoes/august_stramm.htm $>$. Acesso em: 18 jun. 2018.

Recebido em: 24 de outubro de 2018 Aprovado em: 8 de novembro de 2018 